\title{
Performance of Plasma B-Type Natriuretic Peptide as a Diagnostic Biomarker in Heart Failure
}

\author{
MM Hoque ${ }^{1}$, S Shafiullah $^{1}$, P Sultana $^{2}$, N Sultana ${ }^{3}$ \\ ${ }^{1}$ Dept. of Biochemistry, BSMMU. ${ }^{2}$ Dept. of Biochemistry, Shaheed Suhrawardi Medical College. \\ ${ }^{3}$ Dept. of Biochemistry, Dhaka Medical College.
}

Keywords:
BNP,
Heart failure.

\begin{abstract}
:
\end{abstract}
Background: Accurate diagnosis of heart failure (HF) is essential for its proper management and logical drug therapy to reduce morbidity and mortality. On this perspective researcher are in search of a good biomarker as complementary to the clinical parameters to improve the performance of $\mathrm{HF}$ diagnosis. B-type natriuretic peptide (BNP) secreted by cardiac ventricles in HF has emerged as a new promising biomarker in this regard.

Objective: To evaluate the performance of plasma BNP as a diagnostic biomarker in HF.

Methods: In a cross sectional study 180 clinically suspected HF patients were selected. Their plasma BNP were measured and then subjected to echocardiogram. Patients were categorized as HF and without HF on the basis of echocardiogram and against this information the performance of plasma BNP of study subjects were evaluated as a diagnostic biomarker of HF considering $100 \mathrm{pg} / \mathrm{ml}$ as its cut off point.

Results: Sensitivity, specificity, accuracy, PPV, NPV, PLR and NLR of plasma BNP for diagnosis of HF found to be $88 \%, 63.8 \%, 77.2 \%, 75.2 \%, 81.0 \%, 2.4$ and 0.2 respectively.

Conclusion: Plasma BNP concentration increases in HF. Based on $100 \mathrm{pg} / \mathrm{ml}$ as cut off point, plasma BNP shows good performance in diagnosis of $\mathrm{HF}$.

(Cardiovasc. j. 2011; 3(2): 126-130)

\section{Introduction:}

Heart failure is a common, highly morbid cardiovascular disorder associated with perturbations in cardiac structure and function; culminating to the failure of heart to meet up the perfusion demand of peripheral tissues.

Incidence of heart failure is gradually increasing. It is nearly as common as diabetes in older adults, occurring in $2 \%$ of the adult population and rising to $3 \%$ in adults over 75 years age. About $35 \%$ of these patients hospitalize annually and $50 \%$ die within 5 years. ${ }^{1}$

For individuals more than 40 years, the lifetime risk of developing heart failure has been estimated to about $20 \%$ for both sexes. The incidence of heart failure is highest in peoples older than 65 years. This segment of population is growing rapidly, ensuring an epidemic of heart failure that will continue to grow as the population ages. ${ }^{2}$ According to Boon et al. ${ }^{3}$ the prevalence of heart failure raises from around $1 \%$ in the age group 50-59 years to about $5-10 \%$ among those aged $80-89$ years.

The most common cause of heart failure is the ischemic heart disease. Due to the seminal improvement in diagnosis and treatment of patients with Acute Coronary Syndrome (ACS) in recent past, more patients are now surviving ACS than in previous decades and are left at risk for development of heart failure. ${ }^{4}$ Half of patients carrying a diagnosis of $\mathrm{HF}$ die within 4 years and in patients with severe HF more than $50 \%$ die within 1 year. ${ }^{5}$ So heart failure is a dreadful condition as far as prognosis is concerned. Good management of heart failure depends on early accurate etiological diagnosis partly because in some situation a specific remedy is available but mainly because a clear understanding of pathophysiology is essential to logical drug therapy. ${ }^{3}$

The classic symptoms of heart failure (e.g. Fatigue, cough, dyspnea, orthopnea, pulmonary edema, 
peripheral edema) are non-specific and not sensitive enough to be used as a basis for accurate diagnosis since other diseases (e.g. COPD) can produce a similar clinical presentation. ${ }^{6}$ The two chief causes of dyspnea, congestive heart failure and lung disease are often difficult to differentiate. ${ }^{7}$ As a result both under and over diagnosis of $\mathrm{HF}$ is common especially in elderly population, obese and patient with underlying lung disease. ${ }^{8}$ In a recent survey in cardiac emergency setting doctors are found to be unsure of the diagnosis of HF in $40 \%$ of patients they encounter. ${ }^{9}$

Many aspects of heart failure still remain clinical challenges. We not only have difficulty in diagnosing heart failure, we have difficulty in assessing the short term and long term results of treatment both in hospital and outpatient's settings.., 10

Until now echocardiogram is regarded as the gold standard laboratory tool to diagnose heart failure in spite of its limitations. Echocardiogram is mostly concerned to characterized the specific structural and functional abnormalities associated with the syndrome but do not determine the diagnosis of heart failure. ${ }^{2}$

Although echocardiogram can detect the systolic dysfunction, however $50 \%$ patients presented with clinical heart failure have normal systolic function and $50 \%$ patients with echocardiographic systolic dysfunction found to have no symptoms of heart failure. Thus low ejection fraction is not synonymous with the diagnosis of heart failure. ${ }^{11}$

Echocardiogram as a conventional cardiac function test is time consuming, costly, not easily accessible especially in an urgent care setting, needs expertise interpretation and often do not correlate well with patients symptomatic scenario. Therefore, health personnel are searching for inexpensive, specific, sensitive, readily available and easily interpretable diagnostic aid to diagnose heart failure irrespective of underling etiopathophysiology. Cardiac natriuretic hormones have been researched for such a diagnostic value. On this perspective B-type natriuretic peptide (BNP) has come to light as an ideal biomarker with high diagnostic and prognostic weight for heart failure patients regardless of its type and causes.
B-type natriuretic peptide (BNP) is a cardiac neurohormone specially secreted from the cardiac ventricles in response to ventricular volume expansion, pressure overload and resultant increased wall tension. ${ }^{9}$

In heart failure the persistent progressive cardiac congestion, elevation of left ventricular filling pressure generates mounting myocardial stress leading to increased BNP synthesis. Plasma BNP concentration increases in heart failure in proportion to its severity. ${ }^{4,12}$

To evaluate the utility of BNP assay, Dao et al. ${ }^{13}$ performed BNP measurement on 250 patients who came to the emergency room for shortness of breath and reviewed afterwards by cardiologists to determine appropriate diagnosis. Emergency doctors made an incorrect diagnosis in $12 \%$ of patients: half were diagnosed as HF but did not have it and HF was missed in the others. Of the 30 incorrect diagnoses, 29 would likely have been correct had BNP measurements been available.

BNP discriminates accurately between cardiac and noncardiac dyspnea, especially in the emergency setting with a high specificity, sensitivity and accuracy. ${ }^{14}$ Maisel and colleagues. ${ }^{4}$ also demonstrated the value of plasma BNP to differentiate dyspnea due to congestive heart failure and other causes. They concluded that the value of plasma BNP in adjunct with other clinical parameters leads to diagnosis of congestive heart failure in acute care setting.

Prevalence of HF in our population is also big and alarmingly increasing. Accurate etiological diagnosis is the spearhead to combat this problem. Due to the limitations of its clinical diagnosis echocardiogram is still regarded as gold standard laboratory approach for diagnosis of HF in spite of its varieties of flaws. On our perspective access to echocardiogram is very limited especially at primary and secondary level of our health care system and particularly in urgent care setting. So in our scenario plasma BNP can easily be exploited for diagnosis, clinical staging, risk assessment and risk stratification of heart failure. Plasma BNP measurement is relatively inexpensive, readily available and easily interpretable in comparison to echocardiogram and found to be suited very much for the poor patients like ours. Therefore, for our population, measurement of plasma BNP hopefully 
will facilitate the rapid correct diagnosis of $\mathrm{HF}$ to reduce its morbidity and mortality in our population.

Large body of evidences is now in a consensus to float plasma BNP as a diagnostic and prognostic biomarker for heart failure patients. However, most of these findings are derived from white population. Works on Asians are relatively few and available data from Bangladesh on this issue is scarce. So, this study aimed to measure the plasma $\mathrm{BNP}$ in HF patients and to evaluate its association with heart failure.

\section{Materials and Methods:}

In a cross sectional study 180 clinically suspected HF patients were selected from the cardiology emergency department of Bangabandhu Sheikh Mujib Medical University (BSMMU) and National Institute of Cardiovascular Disease (NICVD) through convenient sampling during the period of July/ 07 to June/ 08. All study subjects were free from ischemic heart disease, renal failure, non cardiac fluid overload, thyroid disorders and liver diseases. Ethical clearance for the study was taken from the central ethical committee BSMMU and informed written consent of all study subjects were taken prior to their enrollment.

All selected study subjects were subject to ECG and echocardiogram and their blood sample were collected for plasma BNP measurement. Diagnosis of heart failure was confirmed on the basis of echocardiogram and the patients were categorized into two groups (HF and without HF). Against this information plasma BNP concentration of study subjects were evaluated as the diagnostic biomarker of $\mathrm{HF}$ considering $100 \mathrm{pg} / \mathrm{ml}$ as its cut off point. Measurement of plasma BNP was done by microparticle enzyme immunoassay (MEIA) principle [15]. Data were analyzed using SPSS (version 12.0 for windows). Performance of plasma $\mathrm{BNP}$ as a diagnostic tool of HF was determined by sensitivity, specificity, positive predictive value (PPV), negative predictive value (NPV), positive likelihood ratio (PLR), negative likelihood ratio (NLR) and accuracy.

\section{Results and Observations :}

In this cross sectional study on 180 clinically suspected HF cases, 100 patients were finally diagnosed as $\mathrm{HF}$ and 80 patients as without HF. The mean age of $\mathrm{HF}$ cases was 41.1 years and that of non-HF cases was 36.9 years. Between the HF and non-HF cases plasma BNP found elevated in 88 and 29 patients respectively. For diagnosis of HF sensitivity, specificity, accuracy, PPV, NPV, PLR and NLR of plasma BNP found to be $88 \%$, $63.8 \%, 72.2 \%, 75.2 \%, 81 \%, 2.4$ and 0.2 respectively.

Table-I

Age and sex distribution of study subjects

\begin{tabular}{lccccc}
\hline Subject & Total number & Mean age (yr) & Age range & M & F \\
\hline Subjects with heart failure & 100 & 41.1 & $10-70$ & 61 & 39 \\
Subjects without heart failure & 80 & 36.9 & $15-70$ & 40 & 40 \\
\hline
\end{tabular}

Table-II

Distribution of study subjects according to plasma BNP concentration

\begin{tabular}{lccc}
\hline $\begin{array}{l}\text { Plasma BNP } \\
(\mathrm{pg} / \mathrm{ml})\end{array}$ & $\begin{array}{c}\text { Subject with HF } \\
\text { (Echo positive) }\end{array}$ & $\begin{array}{c}\text { Subjects without HF } \\
\text { (Echo negative) }\end{array}$ & Total \\
\hline$>100$ & 88 & 29 & 117 \\
$<100$ & 12 & 51 & 63 \\
\hline Total & 100 & 80 & 180 \\
\hline
\end{tabular}

Table-III

Performance of plasma BNP as a diagnostic tool of $\mathrm{HF}$

\begin{tabular}{lcccccc}
\hline Sensitivity & Specificity & Accuracy & PPV & NPV & PLR & NLR \\
\hline $88 \%$ & $63.8 \%$ & $77.2 \%$ & $75.2 \%$ & $81 \%$ & 2.4 & 0.2 \\
\hline
\end{tabular}

Cut off value of plasma BNP $=100 \mathrm{pg} / \mathrm{ml}$ 


\section{Discussion:}

On the basis of the empirical cut off value of 100 $\mathrm{pg} / \mathrm{ml}$ for BNP in the diagnosis of $\mathrm{HF}$, as proposed by McCullough et al. ${ }^{9}$ and Wieczorek et al. ${ }^{16}$ our study showed the sensitivity, specificity positive predictive value (PPV), negative predictive value (NPV), positive likelihood ratio (PLR), negative likelihood ratio (NLR) and accuracy of plasma BNP as a diagnostic marker of $\mathrm{HF}$ to be $88 \%, 63.8 \%$, $75.2 \%, 81.0 \%, 2.4,0.2$ and $77.2 \%$ respectively. Cowei et al. ${ }^{17}$ showed sensitivity, specificity, PPV and NPV $97 \%, 48 \%, 70 \%$ and $98 \%$ respectively with a cut off value $\geq 76.81 \mathrm{pg} / \mathrm{ml}$. Since at low cut off value sensitivity and NPV increases with decreased specificity, probably for this reason in this study researcher got higher sensitivity and NPV with lower specificity than those of ours because our cut off value was $100 \mathrm{pg} / \mathrm{ml}$ compare to $76.81 \mathrm{pg} / \mathrm{ml}$ in their study. Maisel et al. ${ }^{4}$ observed sensitivity, specificity, accuracy, PLR and NLR $90 \%, 76 \%, 83 \%, 3.75$ and 0.13 respectively in their study. Our result is very close to this. McCullough et al. ${ }^{9}$ and Wieczorek et al. ${ }^{16}$ observed sensitivity $90 \%$ and $82 \%$, specificity $73 \%$ and 99 $\%$ respectively with the cut off value $100 \mathrm{pg} / \mathrm{ml}$, whereas Tjerdsma et al. ${ }^{18}$ found sensitivity $91 \%$ and specificity $92 \%$ with a cut off value $69.2 \mathrm{pg} /$ ml. Lainchbury et al. ${ }^{19}$ in their study found sensitivity, specificity, accuracy, PPV, NPV, PLR and NLR to be $97 \%, 49 \%, 65 \%, 49 \%, 97 \%, 2.77$ and 0.06 respectively. Our results are consistent with these findings in some respects and even better in some other respects.

Maisel et al. ${ }^{20}$ evaluated the performance of plasma BNP concentration in non-systolic $\mathrm{HF}$ at cut off $100 \mathrm{pg} / \mathrm{ml}$ and found sensitivity $86 \%$, accuracy 75 $\%$ and NPV $96 \%$ which also supports our results except the NPV. Hammwerer-Lercher et al. ${ }^{21}$ in his study on left ventricular dysfunction found sensitivity $73 \%$ and specificity $77 \%$. Lubien et al. ${ }^{22}$ with cut off point $62 \mathrm{pg} / \mathrm{ml}$ in diastolic dysfunction of heart found sensitivity $85 \%$, specificity $83 \%$ and accuracy $84 \%$. Apple et al. ${ }^{23}$ with cut off point $>100 \mathrm{pg} / \mathrm{ml}$ found sensitivity $94.8 \%$, specificity $77.1 \%$, PPV $85.3 \%$ and NPV $91.4 \%$. All these findings are more or less harmonious with those of ours.

Peacock ${ }^{24}$ in his review of several studies with various cut off points reported the sensitivity $85 \%$ to $97 \%$, specificity $84 \%$ to $92 \%$, PPV $70 \%$ to $95 \%$ and NPV $>95 \%$. On this perspective our result is well in agreement in respect of sensitivity and PPV but not in respect of specificity and NPV.

Performance of plasma BNP as a diagnostic tool of $\mathrm{HF}$ proposed by different researchers in fact varies because of the different cut off point used by different researchers as well as of different types of $\mathrm{HF}$ patients enrolled in different research setting. In spite of these our results are nearly consistent with those of others except that our results have shown less specificity compared to some published data. Low specificity tends to make more false positive diagnosis and on the perspective of present exciting advances in the non-invasive medical treatment of HF; false positive diagnosis is less traumatic than false negative.

So results of our study advocates in favor of the raised plasma BNP to be used as a biomarker for diagnosis of $\mathrm{HF}$ considering the cut off point $100 \mathrm{pg} / \mathrm{ml}$.

Conflict of Interest - None.

\section{Conclusion:}

In $\mathrm{HF}$, plasma BNP concentration increases due to its synthesis by cardiac ventricles. So plasma BNP can be used as a diagnostic biomarker of HF. In this study performance of plasma BNP as diagnostic biomarker of $\mathrm{HF}$ with respect to sensitivity, specificity, accuracy, PPV, NPV, PLR and NLR found to be $88 \%, 63.8 \%, 77.2 \%, 75.2 \%$, $81.0 \%, 2.4$ and 0.2 respectively.

\section{References:}

1. Frank, J. Congestive heart failure and brain natriuretic peptide. PSA Consult 2002; 14:4-5.

2. Lloyd-Jones, DM. The risk of congestive heart failure: Sobering lessons from the Framingham Heart Study. Curr Cardiol Rep 2001;3(3):184-190.

3. Boon, NA, Fox, KAA, Bloomfield, P, Bradbury, A. Cardiovascular disease. In: Haslett, C, Chilvers, ER, Boon, NA, Colledge, NR, Eds. Davidson's Principles and Practice of Medicine. $19^{\text {th }}$ edn, Edinburgh: Churchill Livingstone, 2002: 381-385.

4. Maisel, AS, Krishnaswamy, P, Nowak, RM, McCord, J, Hollandar, JE, Duc, P et al. Rapid measurement of Btype natriuretic peptide in the emergency diagnosis of heart failure. N Engl J Med 2002; 347(3): 161-167.

5. Swedberg, K, Cleland, J, Dargie, H, Drexler, H, Follath, F, Komajda, M, Tavazzi, L, Smiseth, OA. Guidelines for the diagnosis and treatment of chronic heart failure: executive summary (update 2005). European heart Journal 2005; 26:1115-1140. 
6. Stevenson, LW, Perloff, JK. The limited reliability of physical sings for estimating hemodynamics in chronic heart failure. JAMA 1989; 261(6): 884-888.

7. Schmitt, BP, Kushner, MS, Wiener, SL. The diagnostic usefulness of the history of the patient with dyspnea. Journal of General Internal Medicine 1986; 1(6): 386393.

8. Redfield, MM. The breathing not proper trial: enough evidence to change heart failure guidelines? J Card Fail 2002; 8: 120-123.

9. McCullugh, PA, Nowak, RM, McCord, J, Hollander, JE, Herrmann, HC, Steg, PG et al. B-type natriuretic peptide and clinical judgment in emergency diagnosis of heart failure. Circulation 2002;106: 416-422.

10. Vinson, JM, Rich, MW, Sperry, JC, Shah, AS, Mcnamara, T.'Early readmission of elderly patients with congestive heart failure. J Am Geriatr Soc 1990; 38(12): 1290-1295.

11. Senni, M, Redfield, MM. Heart failure with preserved systolic function. J Am Coll Cardiol 2001; 38: 1277 1282.

12. Schrier, RW, Abraham, WT. Hormones and hemodynamics in heart failure. N Engl J Med 1999; 341(8) : 577-585.

13. Dao, Q, Krishnaswamy, P, Kazanegra, R, Harrison, A, Amirnovin, R, Lenert, L, Clopton, P, Alberto, J, HIavin, $\mathrm{P}$, Maisel, AS. Utility of B-type natriuretic peptide in the diagnosis of congestive heart failure in an urgentcare setting. J Am Coll Cardiol 2001; 37: 379-385.

14. Morrison, LK, Harrison, A, Krishnaswamy, P, Kazanegra, R, Clopton, P, Maisel, A. Utility of a rapid Bnatriuretic peptide assay in differentiating congestive heart failure from lung disease in patients presenting with dyspnea. J Am Coll Cardiol 2002; 39: 202-209.

15. Axis-Shield Diagnostic. Estimation of plasma BNP, In: Operation manual for AxSYM. BNP. USA, Abbott Laboratories: 2003.
16. Wieczorek, SJ, Wu, AHB, Christenson, R, Krishnaswamy, P, Gottlieb, S, Rosano, T et al. A rapid B-type natriuretic peptide assay accurately diagnoses left ventricular dysfunction and heart failure: A Multicenter Evaluation. Am heart J 2002; 144: 834-839.

17. Cowei, MR, Sruthers, AD Wood, DA, Coats, AG, Thompson, SJ, Pool-Wilson, PA, Sutton, GC. Value of natriuretic peptide in assessment of patients with possible new heart failure in primary care. Lancet 1997; 350: 1349-1353.

18. Tjeerdsma, G, DeBoer, RA, Boomsma, F, Vandenberg, M, Pinto, YM, Vanveldhuisen, DJ. Rapid bedside measurement of brain natriuretic peptide in patients with chronic heart failure. International Journal of Cardiology 2002; 86 (23): 143-149.

19. Lainchbury, JG, Campbell, E, Frampton, CM, Yandle, TG, Nicholls, MG, Richards, AM. Brain natriuretic peptide and $\mathrm{N}$-terminal brain natriuretic peptide in the diagnosis of heart failure in patients with acute shortness of breath. J Am Coll Cardiol 2003; 42: 728735 .

20. Maisel, AS, McCord, J, Nowak, RM, Hollander, JE, Wu, AHB, Duc, $\mathrm{P}$ et al. Bedside B-Type natriuretic peptide in the emergency diagnosis of heart failure with reduced or preserved ejection fraction. J Am Coll Cardiol 2003; 41: 2010-2017.

21. Hammwerer-Lercher, A, Neubauer, E, Muller, S, Pachinger, O, Puschendrof, B, Mair, J. Head to head comparison of NT-proBNP, BNP \& NT-pro-ANP in diagnosis left ventricular dysfunction. Clin Chim Acta 2001; 310: 193-227.

22. Lubien, E, DeMasrid, A, Krishnaswamy, P, Clopton, P, Koon, J, Kajanegra, R. Utility of BNP in detecting diastolic dysfunction: comparison with doppler velocity recording. Circulation 2002; 105: 595-601.

23. Apple, FS, Trinity, E, Steen, J, Prawer, S, Wu, AHB. BNP test utilization for CHF in community hospital practice. Clin Chim Acta 2003; 328:191-193.

24. Peacock, WF. The B-type natriuretic peptide assay: A rapid test for heart failure. Cleaved Clinic Journal of Medicine 2002; 69(3): 243-251. 